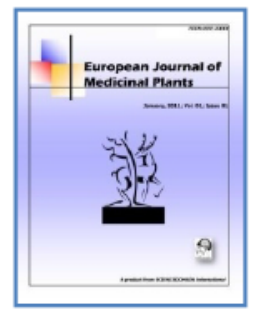

\title{
Fibroblast Growth Stimulation, DPPH Antioxidant Assay and Antimicrobial Activities of Funtumia elastica (Preuss) Stapf (Apocynaceae) Leaf Extracts
}

\author{
Samuel N. Osei-Djarbeng ${ }^{1,4^{\star}}$, Sally J. Cutler ${ }^{2}$, Ronald R. Cutler ${ }^{3}$ \\ and Olivia Corcoran ${ }^{1}$ \\ ${ }^{1}$ Medicines Research Group, School of Health, Sports and Bioscience, University of East \\ London, Stratford Campus, Water Lane, London, E15 4LZ, UK. \\ ${ }^{2}$ Infection and Immunity Research Group, School of Health, Sports and Bioscience, \\ University of East London, Stratford Campus, Water Lane, London, E15 4LZ, UK. \\ ${ }^{3}$ School of Biological and Chemical Sciences, Queen Mary, University of London, Mile End \\ Road, London, E1 4NS, UK. \\ ${ }^{4}$ Department of Pharmaceutical Sciences, Faculty of Medicine and Health Sciences, Kumasi \\ Polytechnic, P. O. Box 854, Kumasi, Ghana.
}

\section{Authors' contributions}

The work was undertaken with collaboration among all the authors. Author SNOD carried out the entire work and wrote the first draft. Authors RRC, SJC and OC supervised the study, proof read and corrected the final draft. All authors did read and approve the final manuscript.

Original Research Article

Received $3^{\text {rd }}$ February 2014

Accepted 23 ${ }^{\text {rd }}$ March 2014

Published $29^{\text {th }}$ March 2014

\section{ABSTRACT}

Aims: To investigate the scientific basis for the wound-healing properties of Funtumia elastica (Apocynaceae) leaf extracts using relevant in vitro fibroblast growth stimulation, antimicrobial and DPPH-antioxidant assays.

Place and Duration of Study: School of Health, Sports and Bioscience (Bioscience Laboratories), University of East London in the United Kingdom, between July 2007 and May 2010.

Methodology: Methanolic extract of the leaves, and petroleum ether, ethyl acetate, $n$ butanol and aqueous fractions partitioned thereof were tested for antimicrobial activities 
against common wound pathogens (such as Staphylococcus spp, Pseudomonas aeroginosa and Escherichia coli). The Broth dilution method was used to determine the minimum inhibitory concentrations (MIC) of the extracts and fractions. The antioxidant activities were also determined using a 2, 2-diphenyl-1-picrylhydrazyl (DPPH) free radical assay; whilst the ability to stimulate fibroblast growth was investigated using the MTT (3[4, 5-dimethylthiazol-2-yl]-2, 5-diphenyltetrazolium bromide) assay.

Results: The $n$-butanol fraction exhibited the greatest overall activities. It stimulated the growth of fibroblast cells by $28 \%$, and showed MIC range of $0.13-1.0 \mathrm{mg} / \mathrm{mL}$ against the Staphylococci species, P. aeruginosa, Bacillus subtilis and E. coli. The non-polar petroleum ether fraction exhibited MICs greater than $2.0 \mathrm{mg} / \mathrm{mL}$ against all the organisms. All the fractions exhibited antioxidant activities greater than or comparable to that of ascorbic acid.

Conclusion: Collectively, the antioxidant activity, fibroblast growth stimulation and the antimicrobial activities demonstrated by $F$. elastica leaf extracts provide some evidence to support the use of the plant to manage wounds in African folklore medicine.

Keywords: Wound-healing; Funtumia elastica; fibroblast; antioxidant; antimicrobial; DPPH.

\section{INTRODUCTION}

In many parts of Africa including Ghana, herbal medicine continues to be the main source of medication to the population. As part of a global wound-healing research programme, we encountered Funtumia elastica (Preuss) Stapf., a medicinal plant belonging to the family Apocynaceae. The plant has many names including bush rubber, Ive rubber, Lagos rubber, Lagos silk rubber tree, silk rubber and West African rubber tree. The genus name Funtumia, is based on the Ghanaian (Akan) vernacular 'funtum' for the plant [1].

The bark of the plant is astringent and is taken in alcohol to cure haemorrhoids in Nigeria and Ghana [2]. F. elastica is also used to treat problems associated with dysmenorrhoea and blennorrhoea and is further used as laxative and vermifuge. The leaf is mixed with Phyllanthus muellerianus to treat male infertility and also used in the treatment of sexually transmitted diseases (STDs) of bacterial origin [3]. In Congo the plant is used for respiratory conditions, particularly whooping-cough in children and the powdered bark is employed in managing respiratory diseases such as asthma [4]; one such preparation is available commercially at selected clinical outlets in the UK. In addition, $F$. elastica is used in rural Ghana to clean and treat wounds, and thus came to our attention.

The family Apocynaceae to which the plant belongs is rich in alkaloids especially indole and cardenolide types; the Funtumia genus is noted for the presence of steroidal alkaloids, with most containing a conanine basic skeletal structure. The alkaloidal compounds isolated include conkurchine, irehdiamines (A and $B$ ), irehamine and irehine from the leaves [5]; conessine, conamine, irehdiamine, and tetramethyl-horrhimine from the seeds [3]. Cyclofuntumienol and cycloeucalenol have been isolated from the bark and leaves [6]; and holarrhetine, holarrhessine, isoconessine, as well as conessine from the bark [7].

Many West African medicinal plants including the following have been reported to have wound healing properties in traditional medicine; Tridax procumbens [8], Ficus asperifolia and Gossypium arboretum [9] and Bridelia ferruginea [10]. In all these the wound healing properties of the plants were attributed to their antimicrobial, antioxidant and their ability to stimulate the growth of fibroblast cells. In this study the aim was to investigate the wound 
healing potential of the crude methanolic extract (and petroleum ether, ethyl acetate, $n$ butanol and aqueous fractions thereof) of Funtumia elastica (Preuss) Stapf. using In-vitro tests relevant to wound-healing such as anti-oxidant activity, fibroblast growth stimulation and antimicrobial susceptibility.

\section{MATERIALS AND METHOD}

\subsection{Extract Preparation}

Leaves of Funtumia elastica (Preuss) Stapf. were collected in the Ashanti Region of Ghana in October 2007 and authenticated by senior research officer (Dr. G.H. Sam) at the Department of Herbal Medicine, College of Health Sciences at the Kwame Nkrumah University of Science and Technology in Kumasi, Ghana, where a voucher specimen, KNUST/HM1/09/L024, has been deposited. The leaves were washed in water, chopped into pieces and sun-dried, followed by drying in an oven at $40^{\circ} \mathrm{C}$ for $48 \mathrm{~h}$ before being powdered finely using a hammer mill. The powdered sample was sealed in brown paper bags (envelopes) until required.

The plant material was extracted using cold maceration. The material was soaked in methanol, left for three days with occasional stirring and then filtered. The process was repeated twice by addition of more methanol to the residue and filtered again. All filtrates were pooled together and the methanol evaporated in vacuo. A gummy mass was finally obtained and labelled (as F). This methanolic extract (F) was 'suspended' in one part of methanol followed by nine parts of sterile water. The suspension was partitioned in petroleum ether (60-80). This fraction was separated and more petroleum ether was added to the aqueous portion to effect maximum extraction of the petroleum ether soluble components in the plant. The aqueous portion was further partitioned in ethyl acetate, separated and the process repeated. The remaining aqueous fraction was again partitioned in $n$-butanol and the above procedure repeated. The fractions were labelled petroleum ether $(A)$, ethyl acetate (B), $n$-butanol (C), and the residual aqueous fraction (D).

\subsection{Antimicrobial Assay}

Both Gram negative and Gram positive bacteria were used. The Gram negative bacteria were Pseudomonas aeruginosa (ATCC 27853), Escherichia coli (ATCC 25922); whilst Gram positives were Staphylococcus epidermidis (NCTC 11047), Staphylococcus aureus (NCTC 7447), local isolates of methicillin resistant Staphylococcus aureus (PY1311, T3), Bacillus subtilis (NCIMB 3610) and Streptococcus pneumonia (ATCC 6303). The only fungus used was the yeast-like fungus Candida albicans (NCPF 3179).

Cultures of these organisms were prepared in Muller-Hinton broth (Sigma) and incubated at $37^{\circ} \mathrm{C}$. The methanolic extract and fractions of the plant were reconstituted in $10 \%$ methanol followed by dilution with Muller-Hinton broth to make up the volume. The minimum inhibitory concentrations (MICs) of the extracts and the controls were determined using the microtitre well dilution method [11], with triplicate wells and three (3) independent experiments. Extracts and fractions were serially diluted two-fold with broth to give a dilution range of $2 \mathrm{mg} / \mathrm{mL}$ to $2 \mu \mathrm{g} / \mathrm{mL}$ in sterile 96 well microtitre plates.

One hundred microlitres $(100 \mu \mathrm{L})$ of overnight broth culture of organisms $\left(10^{6} \mathrm{CFU} / \mathrm{mL}\right)$ was added to each well, and incubated at $37^{\circ} \mathrm{C}$ for $18-24 \mathrm{~h}$. Control wells did not contain test 
extracts or fractions, and the vehicle control wells contained scalar dilutions of $10 \%$ methanol. Serial dilution of gentamicin (from 1024 to $1 \mu \mathrm{g} / \mathrm{mL}$ ) was used as the positive control. The plates were examined for growth after $18 \mathrm{~h}$. The MIC values were confirmed by addition of $40 \mu \mathrm{L}$ of $0.2 \mathrm{mg} / \mathrm{mL}$ concentration of $\rho$-iodonitrotetrazolium (INT) violet to each well, incubated at $37^{\circ} \mathrm{C}$ for further $30 \mathrm{~min}$, and observed for colour change from purple to pale yellow.

\subsection{DPPH Anti-oxidant Activity}

A DPPH radical assay that has now become the standard for evaluation of in vitro antioxidant activity was used [12]. Initial rapid screening was conducted by loading aliquots $(15 \mu \mathrm{L})$ of each extract and the fractions of $F$. elastica onto a $20 \times 20 \mathrm{~cm}$ TLC layer of $0.5 \mathrm{~mm}$ thickness (Silica gel 60 F254), dried and then developed in ethyl acetate : petroleum ether (2:3) and acetone : petroleum ether (1:2) as solvent systems. When plates were sprayed with DPPH $(40 \mu \mathrm{g} / \mathrm{mL})$ discrete spots with antioxidant activity appeared pale yellow providing initial data as to whether the extracts contained antioxidant activity. Serial dilutions of the crude extract and all the fractions were prepared to give concentration range of $128 \mu \mathrm{g} / \mathrm{mL}$ down to $1.0 \mu \mathrm{g} / \mathrm{mL}$. Each dilution $(0.5 \mathrm{~mL})$ was added to $3 \mathrm{~mL}$ DPPH $(40 \mu \mathrm{g} / \mathrm{mL})$ in methanol. The solutions and a blank DPPH were kept in the dark for 30 minutes and the absorbance read at $517 \mathrm{~nm}$. Ascorbic acid (AA) at the same concentration range as the extracts was used as a positive control for an anti-oxidant agent. Experiments were run in triplicate.

Results of the assay were expressed as 'radical scavenging activity' or 'percentage inhibition of free radical' and these were achieved by relating the absorbance of the sample antioxidant-DPPH mixture with that of DPPH without antioxidants according to the formula [l];

$$
\% \text { Inhibition (DPPH Scavenging Activity })=(A c-A s / A c) \times 100 \% \ldots \ldots .
$$

Where Ac-Absorbance of blank

As - Absorbance of sample

\subsection{In-vitro Test for Fibroblast Growth Stimulation}

Stripped and harvested fibroblast foreskin (FS5) cells were re-suspended in $\mathrm{MEM} / 10 \% \mathrm{FCS} / \mathrm{L}-$ Glutamine [9] and cells counted and standardised to a concentration of $1 \times 10^{4}$ cells $/ \mathrm{mL}$. These cells were seeded in a 96-well plate at a density of $1 \times 10^{3}$ cells $/$ well. The plates were maintained at $37^{\circ} \mathrm{C}$ for $24 \mathrm{~h}$ in a humidified incubator of $5 \% \mathrm{CO}_{2} / 95 \%$ air atmosphere. The medium was replaced with MEM containing $0.5 \%$ FCS and a series of twofold dilutions of the extract and fractions.

Two control columns, one containing MEM/0.5\%FCS/L-Glutamine (maintenance) and the other containing MEM $/ 10 \% \mathrm{FCS} / \mathrm{L}$-Glutamine (positive stimulation) were used, and the plates were incubated at $37^{\circ} \mathrm{C}$ in $5 \% \mathrm{CO}_{2}$, and assayed after four days. The assay was validated by assessing the activity of the most active and least active concentrations on growth of the cells in parallel as counted using a haemocytometer. Cell growth was determined using the MTT [3-(4,5-dimethythiazol-2-yl)-2,5-diphenyl tetrazolium bromide] assay [9]. 


\subsection{Statistical Analysis}

The experiments were run in triplicates; and one-way analysis of variance (ANOVA) was used to compare the averages (data was taken to be significant as $P<.05$ ). The results were expressed as Mean \pm SD (standard deviation) data using Microsoft Excel (Windows 2007).

\section{RESULTS AND DISCUSSION}

Many plants claimed to have anti-microbial activities are often used in the management of wounds, including cuts and burns. The crude methanolic extract and fractions of $F$. elastica leaf showed inhibition of common wound pathogens (Table 1). All the extracts gave an MIC in the range of $0.13-2.00 \mathrm{mg} / \mathrm{mL}$ against the organisms used in the study except the petroleum ether fraction (fraction A) which gave values above $2.00 \mathrm{mg} / \mathrm{mL}$. The extracts exhibited a relatively greater antimicrobial susceptibility to the Gram-positive organisms than the Gram-negatives. Most of the organisms (such as Staphylococcus aureus and Pseudomonas aeroginosa) used in the study are implicated in wound [13].

Table 1. Antimicrobial activities of methanolic extract and partitions of the leaf of F. elastica $(n=3)$

\begin{tabular}{llllll}
\hline & MICs & (mg/mL) & of Extracts & \\
\hline Organisms & F & A & B & C & D \\
Staphylococcus aureus (NCTC 7447) & 1.00 & $>2.00$ & 1.00 & 0.25 & 0.25 \\
Staphylococcus epidermidis (NCTC 11047) & 0.50 & $>2.00$ & 0.50 & 0.25 & 0.25 \\
Methicilin resistant Staphylococcus aureus & 1.00 & $>2.00$ & 1.00 & 0.25 & 0.50 \\
(PY1311, T3) & & & & & \\
Bacillus subtilis (NCIMB 3610) & 0.25 & $>2.00$ & 0.50 & 0.13 & 0.25 \\
Streptococcus pneumoniae (ATCC 6303) & 1.00 & $>2.00$ & 1.00 & 0.50 & 0.50 \\
Pseudomonas aeruginosa (ATCC 27853) & 2.00 & $>2.00$ & 2.00 & 1.00 & 2.00 \\
Escherichia coli (ATCC 25922) & 2.00 & $>2.00$ & 2.00 & 1.00 & 2.00 \\
Candida albicans (NCPF 3179) & 2.00 & $>2.00$ & 1.00 & 0.50 & 1.00 \\
\hline
\end{tabular}

The triplicate experiments gave the same MIC

Key: F-Methanolic extract of $F$. elastica leaf; A-Petroleum ether fraction; B-Ethyl Acetate fraction; C- $n$-Butanol fraction; D-Aqueous fraction.

MIC-Minimum Inhibitory Concentration

The $n$-butanol fraction (C) showed the overall greatest antimicrobial activities followed by that of the aqueous fraction indicating that the antimicrobial constituents of the plant may be polar in nature.

Antioxidant activities comparable to that of ascorbic acid were exhibited by the methanolic leaf extract and all the fractions except the petroleum ether (fraction A). From Table 2 the crude methanol extract gave $70 \%$ inhibition at $16 \mu \mathrm{g} / \mathrm{mL}$, whilst the petroleum ether fraction (A) gave $27 \%$. The $n$-butanol (C) and ethyl acetate (B) fractions gave $93 \%$ and $71 \%$ respectively; whilst the aqueous fraction (D) and the positive control ascorbic acid gave $60 \%$ and $75 \%$ inhibition. In general the $n$-butanol fraction exhibited the most potent antioxidant activities, and the least activity was by the petroleum ether fraction. Potent antioxidants are known to promote wound healing. For example, Raxofelast, a pharmaceutical anti-oxidant agent, is claimed to promote wound healing by reducing lipid peroxidation, neutrophil 
infiltration, oedema, and stimulates re-epithelialization, neo-vascularization, synthesis and maturation of extracellular matrix [14].

Preliminary phytochemical studies of the methanolic extract of the leaf showed the presence of tannins, flavonoids (including anthocyanins), glycosides, saponins and alkaloids. Tannins and flavonoids are known for their potent antioxidant activities [15,16]; presence of these compounds in the plant may be responsible for the good DPPH anti-oxidant activities observed.

Table 2. DPPH antioxidant activities (expressed as percentage (\%) inhibition of free radicals) of methanolic extract and partitions of $F$. elastica leaf $(n=3)$

\begin{tabular}{|c|c|c|c|c|c|c|}
\hline \multirow{2}{*}{$\begin{array}{l}\text { Conc. } \\
(\mu g / m L)\end{array}$} & \multicolumn{4}{|c|}{$\%$ Inhibition of free radicals } & \multirow[b]{2}{*}{$\bar{D}$} & \multirow[b]{2}{*}{$\overline{A A}$} \\
\hline & $\boldsymbol{F}$ & $A$ & $B$ & $\mathbf{C}$ & & \\
\hline 1 & $31.9 \pm 2.5$ & $8.6 \pm 1.3$ & $24.4 \pm 1.2$ & $31.3 \pm 3.1$ & $32.6 \pm 1.8$ & $31.5 \pm 2.0$ \\
\hline 2 & $32.3 \pm 3.1$ & $9.2 \pm 2.2$ & $25.5 \pm 2.1$ & $36.5 \pm 2.4$ & $39.6 \pm 3.0$ & $35.9 \pm 2.1$ \\
\hline 4 & $38.4 \pm 1.6$ & $12.7 \pm 1.4$ & $34.3 \pm 1.5$ & $52.1 \pm 1.9$ & $44.4 \pm 2.8$ & $57.3 \pm 4.1$ \\
\hline 8 & $48.3 \pm 1.7$ & $15.1 \pm 2.0$ & $47.5 \pm 4.1$ & $64.6 \pm 2.7$ & $50.6 \pm 2.1$ & $68.2 \pm 3.5$ \\
\hline 16 & $70.2 \pm 3.5$ & $27.3 \pm 2.4$ & $71.2 \pm 4.2$ & $93.0 \pm 3.8$ & $60.2 \pm 3.3$ & $74.9 \pm 2.1$ \\
\hline 32 & $93.6 \pm 4.1$ & $36.1 \pm 2.4$ & $91.5 \pm 4.0$ & $94.6 \pm 2.3$ & $83.1 \pm 2.9$ & $90.2 \pm 5.3$ \\
\hline 64 & $94.1 \pm 2.7$ & $50.2 \pm 2.7$ & $93.9 \pm 3.7$ & $94.8 \pm 2.9$ & $94.0 \pm 4.3$ & $93.9 \pm 5.8$ \\
\hline 128 & $93.1 \pm 3.1$ & $82.6 \pm 3.5$ & $94.1 \pm 3.7$ & $95.6 \pm 4.0$ & $95.0 \pm 4.7$ & $94.6 \pm 4.9$ \\
\hline
\end{tabular}

Key: F, A, B, C and D - As under Table 1; AA - Ascorbic Acid

Injuries normally produce various free radicals from a diversity of cellular populations through different pathways; and the modulation by antioxidants of generated free radical activity seems to be an important function in pharmacological treatment of wounds. Local ischaemia in wound tissue results in production of many reactive oxygen species (ROS) that can impair normal wound healing by damaging endothelial cells, capillary permeability, and collagen metabolism [17]. In other words, presence of oxygen free radicals can hamper the process thereby seriously delaying wound healing [18]. Antioxidants such as those found in the plant extract and fractions may help mop up free radicals that may be generated as a result of the wound and help in the wound healing process.

Fibroblast stimulation and growth are important in the wound-healing process, especially in the proliferation and the remodelling phases [19]. The $n$-butanol fraction was the only fraction that showed a gradual dose-dependent increase in cell proliferation up to $8 \mu \mathrm{g} / \mathrm{mL}$ (Fig. 1). The gradual increase in proliferation of the cells exhibited as the concentration was increased is due to the fact that more of the agents in the extract that stimulate the growth of the cells were made available. This is expected as most drugs when taken at low doses exhibit little or no detectable effect on the body, but as the dose increases the response also increases, at least up to some level. The activity, however, reduced from $16 \mu \mathrm{g} / \mathrm{mL}$ to the highest concentration of $256 \mu \mathrm{g} / \mathrm{mL}$ used. As the concentration increased from $8 \mu \mathrm{g} / \mathrm{mL}$ the activity declined, perhaps due to saturation of the cells with the increased doses. There was, no toxicity at any of the concentrations used. The highest stimulatory activity observed for this fraction was $28 \%$ compared with the positive control which gave $78 \%$. In the preliminary studies the crude methanolic extract exhibited a maximum increase of $7 \%$ in cell proliferation at a concentration of $32 \mu \mathrm{g} / \mathrm{mL}$.

The petroleum ether, ethyl acetate and aqueous fractions did not show ability to stimulate the growth of the fibroblast cells; they did not also exhibit toxicity against the cells. 
Fibroblast growth stimulation activity has been used to investigate the potential wound healing properties of many plants including Ficus asperifolia and Gossypium arboretum, Bridelia ferruginea, and Terminalia sericea and Gunnera perpensa which are purportedly used for wound healing in Africa. In the case of $B$. ferruginea the growth of FS5 fibroblasts became apparent only at a concentration of $5 \mu \mathrm{g} / \mathrm{mL}$ (where there was $28 \%$ increase). Above this concentration the extracts showed toxicity to the cells [10]. For $F$. asperifolia and $G$. arboretum the plants had good effects on the growth of human dermal fibroblast at concentrations up to $50 \mu \mathrm{g} / \mathrm{mL}$ [9]. For $T$. sericea and G. perpensa, both plant extracts had no significant effect on the growth of the fibroblasts up to concentrations of $1 \mathrm{mg} / \mathrm{mL}[20]$. The $n$-butanol fraction of $F$. elastica compares favourably with some of the mentioned wound healing plants in Africa.

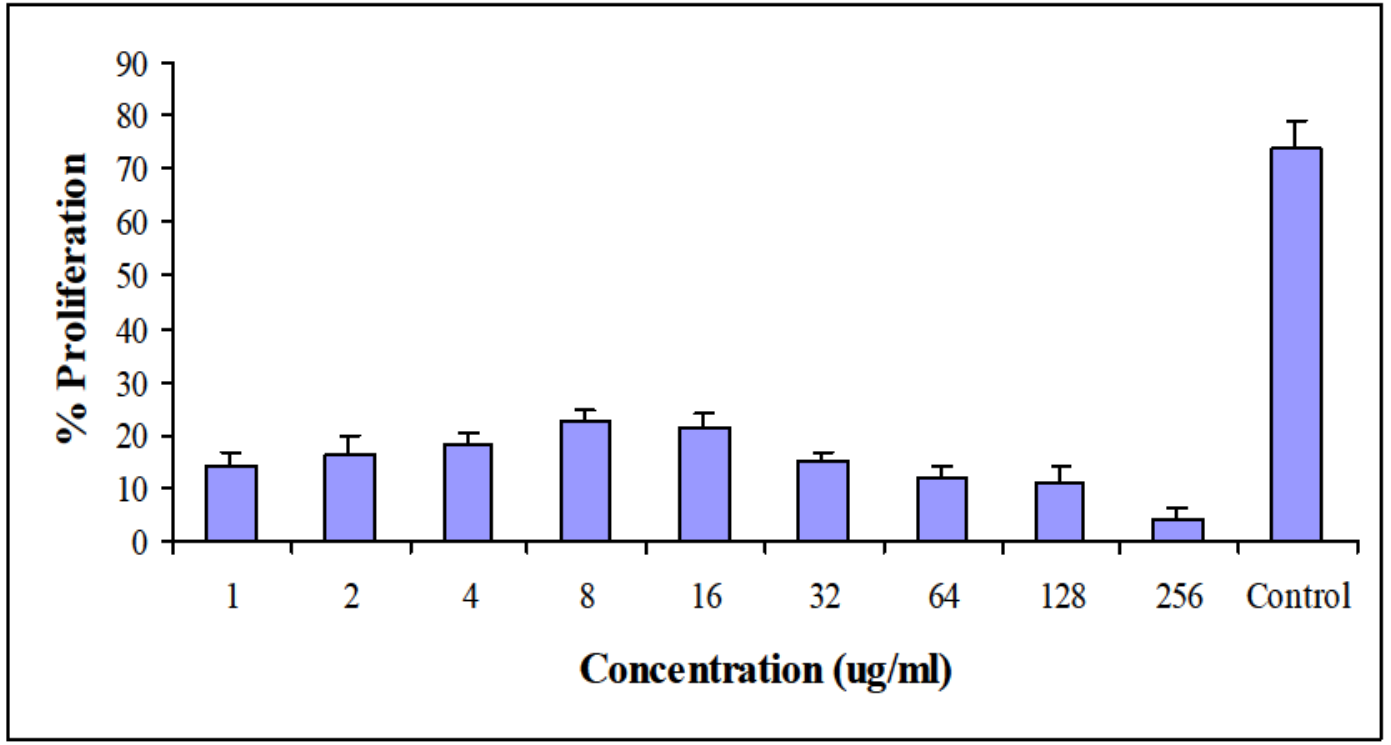

Fig. 1. Fibroblast growth stimulatory activity of $n$-butanol fraction of $F$. elastica leaf expressed as \% Proliferation

The control in the experiment was MEM/10\%FCS/L-Glutamine.(MEM - Minimum Essential Medium, FCS - Foetal Calf Serum)

\section{CONCLUSION}

The methanolic leaf extracts of $F$. elastica (Preuss) Stapf., a plant used in West African folklore medicine to manage wounds, exhibited antimicrobial activity, DPPH antioxidant activity comparable to ascorbic acid, and displayed some ability to stimulate the growth of fibroblast cells in-vitro. Collectively these data may support the use of $F$. elastica leaf preparations in wound healing. 


\section{CONSENT}

Not applicable.

\section{ETHICAL APPROVAL}

Not applicable.

\section{COMPETING INTERESTS}

Authors have declared that no competing interests exist.

\section{REFERENCES}

1. Burkill HM. The useful plants of West Tropical Africa. Royal Botanic Gardens Kew; 1994.

2. Irvine FR. The Woody Plants of Ghana, Oxford University Press, London; 1961.

3. Tolela MDL, Foche P. Minor alkaloids from the seeds of Funtumia elastica of Zaire. Planta Med. 1979;35:48-50.

4. Hedges JF, Graff JC, Wilson S, Freedman B, Schepetkin IA, Quinn MT, Jutila MA. Novel innate polysaccharide agonists derived from Funtumia elastica tree bark. FASEB Journal. 2008;22:672-674.

5. Willaman JJ, Li HL. Alkaloid-bearing plants and their contained alkaloids. Lloydia Supplement. 1970:33.

6. Mukam L, Charles G, Hentchoya J, Njimi T, Ourisson G. Cyclofuntumienol, Methyl- 4sterol from Funtumia elastic. Tetrahedron Lett. 1973;2779.

7. Zirihi GN, Grellier P, Guede-Guede F, Bodo B, Mambu L. Isolation, characterization and anti-plasmodial activity of steroidal slkaloids from Funtumia elastica (Preuss) Stapf., Bio-org. Med. Chem. Letts. 2005;15(10):2637-2640.

8. Udupa SL, Udupa AL, Kulkarni DR. A Comparative study on the effect of some indigenous drugs on normal and steroid depressed healing. Fitoter. 1998;69:507-510.

9. Annan K, Houghton PJ. Antibacterial, antioxidant and fibroblast growth stimulation of aqueous extracts of Ficus asperifolia Miq. and Gossypium arboretum L., woundhealing plants of Ghana. J. Ethnopharmacol. 2008;119:141-144.

10. Adetutu A, Morgan WA, Corcoran O. Antibacterial, antioxidant and fibroblast growth stimulation activity of crude extracts of Bridelia ferruginea leaf, a wound-healing plant of Nigeria. J. Ethnopharmacol. 2011;133:116-119.

11. Eloff JN. Antibacterial activity of 27 South African members of the Combretaceae. S. Afr. J. Sci. 1999;95:148-152.

12. Gil MI, Tomas-Barberan FA, Hess-Pierce B, Holcroft DM, Kader AA. Antioxidant activity of pomegranate juice and its relationship with phenolic composition and processing. J. Agric Food Chem. 2000;48:4581-4589.

13. Giodsbol K, Christensen JJ, Karlsmark T, Jorgensen B, Klein BM, Krogfelt KA. Multiple bacterial species reside in chronic wounds: A longitudinal study. Int. Wound. 2006;3(3):225-231.

14. Galeano M, Torre V, Deodato B, Campo GM, Colonna M, Sturiale A, Squadrito F, Cavallari V, Cucinotta D, Buemi M, Altavilla D. Raxofelast, a hydrophilic vitamin E-like antioxidant stimulates wound healing in genetically diabetic mice. Surgery. 2001;129:467-477. 
15. Sulaiman S, Ibrahim D, Kassim J, Sheh-Hong L. Antimicrobial and antioxidant activities of condensed tannin from Rhizophora apiculata barks. J. Chem. Pharm. Res. 2011;3(4):436-444.

16. Khan RA. Evaluation of flavonoids and diverse antioxidant activities of Sonchus arvensis. Chem. Cent. J. 2012;6:126.

17. Senel O, Cetinkale O, Ozbay G, Ahciog F, Bulan R. Oxygen free radicals impair wound healing in ischemic rat skin. Ann. Plastic Surg. 1997;39:516-523.

18. Mensah AY, Sampson J, Houghton PJ, Hylands PJ, Westbrook J, Dunn M, Hughes MA, Cherry GW. Effects of Buddleja globosa Leaf and its Constituents Relevant to Wound Healing. J. Ethnopharmacol. 2001;77:219-226.

19. Bodeker G, Hughes MA. Wound healing, traditional treatments and research policy. In: Prendergast HDV, Etkin NL, Harris DR, Houghton PJ, editors. Plants for Food and Medicine. Royal Botanic Gardens, Kew, London; 1998.

20. Steenkamp V, Mathivha E, Gouws MC, van Rensburg CEJ. Studies on antibacterial, antioxidant and fibroblast growth stimulation of wound healing remedies from South Africa. J. Ethnopharmacol. 2004;95:353-357.

(c) 2014 Osei-Djarbeng et al.; This is an Open Access article distributed under the terms of the Creative Commons Attribution License (http///creativecommons.org/licenses/by/3.0), which permits unrestricted use, distribution, and reproduction in any medium, provided the original work is properly cited. 